\title{
The challenges and opportunities for research in paleontology for the next decade
}

\author{
Robert R. Reisz ${ }^{1 *}$ and Hans-Dieter Sues ${ }^{2}$ \\ ${ }^{1}$ Department of Biology, University of Toronto Mississauga, Mississauga, ON, Canada, ${ }^{2}$ Department of Paleobiology, \\ National Museum of Natural History, Smithsonian Institution, Washington, DC, USA
}

Keywords: paleontology, interdisciplinary science, paleobiology, evolution, earth history

\section{OPEN ACCESS}

Edited by:

Hugo F. R. Bucher,

University of Zürich, Switzerland

Reviewed by:

Peter D. Roopnarine,

California Academy of Sciences, USA

*Correspondence:

Robert R. Reisz

robert.reisz@utoronto.ca

Specialty section:

This article was submitted to

Paleontology, a section of the journal

Frontiers in Earth Science

Received: 13 October 2014

Accepted: 22 February 2015

Published: 10 March 2015

Citation:

Reisz RR and Sues H-D (2015) The challenges and opportunities for

research in paleontology for the next decade. Front. Earth Sci. 3:9.

doi: 10.3389/feart.2015.00009
Since the recognition of fossils as remnants of once-living organisms by early polymaths such as Leonardo da Vinci and Nicholas Steno, paleontology has become the clearest window into the long history of life on Earth. During much of the nineteenth and twentieth centuries, paleontology was primarily an observational science, focused on the discovery, naming, and description of fossil plants and animals. Of particular note, early discoveries of dinosaurs and other large extinct animals such as proboscideans brought the field of paleontology to the attention of the general public, and the fascination with these strange creatures of the past has continued to grow since that time. A parallel line of inquiry has developed through the use of fossils for working out the succession and relative ages of sedimentary rocks worldwide, establishing a critical link to other earth sciences and the practical utility of palaeontological research. However, especially following the publication of Darwin's magnum opus, paleontologists became increasingly interested in understanding the significance of fossils for reconstructing the history of Life through time. Starting early in the twentieth century, many researchers focused on interpreting extinct organisms as once-living beings and their ecological relationships with their environment and to each other. It is therefore with the acceptance of such processes as origination, evolution and extinction within local, regional and global frameworks, that paleontology really entered the modern era, with researchers studying the evolution of particular groups of organisms and communities through time, and their interactions within and with the biosphere. Thus, paleontology has come to represent a unique field, providing deep-time perspectives on the biological and geological processes of our planet.

The overall purpose of the paleontological section of this journal is to promote excellence in this area of research, focus on topics of particular interest, and publish studies that will carry the field forward in the twenty-first century.

The study of the diversity and distribution of extinct life forms retains a central role in paleontology, much like work on the diversity of extant organisms in biology. Although this core activity is often denigrated as an intellectually inferior exercise by researchers primarily interested in understanding large-scale patterns and processes of evolution, the latter studies stand and fall on the quality of the underlying primary morphological and taxonomic data. Fossils are unique in documenting changes over long intervals of time, and frequently have features and combinations of features not found in extant taxa (Edgecombe, 2010). They also establish the spatial and temporal distribution of organisms. Intense reconnaissance efforts across the globe continue to uncover vast numbers of new or little-known extinct species (Caron et al., 2014), some of which represent novel body plans. Such studies form the bedrock of the discipline, and its support through this journal is critical for the continued vitality of the discipline. However, the nuts-and-bolts approach to this kind of research is already being covered by the specialty journals for each subdiscipline. The Frontier aspect of documenting the history of life on Earth is tied more to the need to integrate the various sub-disciplines of paleontology into the broader study of the fossil record from evolutionary and ecological perspectives (Gill et al., 2014). Increasingly, paleontologists are 
studying entire communities of extinct organisms, permitting more holistic approaches to understanding the ecosystems in which particular life forms or group of organisms lived and the conditions under which they died and were preserved. This approach to the study of the fossil record has become truly interdisciplinary, drawing on a wide range of physical and biological sciences.

Since more than 99 percent of the species that ever lived on this planet are already extinct (Raup, 1986), the number of fossil organisms yet to be discovered remains vast. Ever since Darwin there have been many discussions concerning the relative completeness of the fossil record over the years but numerous recent studies have argued that the quality of the record has been improving (e.g., Wills et al., 2008). Although many aspects of plant and animal evolution have indeed been clarified in recent decades, countless unresolved questions remain. Frequently new fossils (and new approaches to their study) generate more questions than answers. There is a continuing need to integrate new discoveries and new data into the overall evolutionary picture, and examine how they improve our understanding of the evolutionary processes that led to extant life forms and the communities that they form. Thus, major events in the history of life, including the origin, adaptive radiation, and extinction of the major clades are long-term trends that can only be fully understood through the deep-time perspective provided by paleontology. This continues to be a major frontier of paleontology. Recent research on the origin and early diversification of tetrapods provides a particularly impressive example (Clack, 2009).

Phylogenetic research on extant life forms is increasingly based predominantly on molecular data. Dramatic advances in technology have greatly facilitated acquisition and analysis of genomic sequences and other biomolecular information. Indeed, a few researchers have even completely dismissed the relevance of morphological data for phylogeny reconstruction. However, present-day organisms only represent a vanishingly small percentage of all life forms that ever existed on Earth, and most fossils do not preserve biomolecules. Thus, meaningful studies of total biodiversity must involve reciprocal illumination, repeatedly comparing and testing hypotheses generated from molecular data by comparison with morphological information from both extant and extinct species.

Patterns of diversification and extinction, as documented by the fossil record, not only illustrate the history of the biosphere but also offer insights into possible outcomes of major environmental changes in the future. Many researchers are now exploring the biological consequences of the five mass extinctions during the last 540 million years or so and the causative physical processes. This is a particularly relevant field of inquiry at a time when there is increasing concern about the impact of anthropogenic environmental change.

In recent years the issue of climate change has received much attention from the scientific community and the general public. There is general agreement among researchers that climate change profoundly affects biological systems, but it is less wellunderstood how ecosystems and individual species respond to such changes. Both of these are areas in which paleontological research can have a major impact. Palaeoclimatic modeling is now possible through the integration of numerous sources of geological, biological, and chemical information, such as stable isotopes. A greater understanding of the relationship between climate change and the diversification and extinction of ancient organisms and communities provides case studies for assessing future changes in the biosphere (McInerney and Wing, 2011). In looking at the present environmental crisis data on the time frames and rates of changes in the geological past are vitally important for evaluating possible responses of the biosphere to climate changes.

The strength of paleontology is the unique contributions it can make to the understanding of the history of life, like the discoveries of major groups of organisms previously unknown to science, novel body plans, studies of rates of speciation and extinction, and the origins of and subsequent changes in marine and continental ecosystems. The integration of the information provided by the fossil record with geological data will continue to provide critical new insights into such events in the history of life on earth (Dunne et al., 2014). This journal would therefore like to publish papers that integrate geological and palaeobiological data for testing hypotheses of major extinction events.

Other major challenges facing the discipline include keeping up with the revolutionary changes that are occurring in the other natural sciences, and taking full advantage of those changes for maintaining paleontology's role as the primary interpreter of the history of life on Earth. Cutting-edge paleontological research now includes computer modeling for testing hypotheses concerning aspects of the biology of extinct taxa when no extant relatives or even close analogs exist. One elegant example is testing locomotory abilities in large, bipedal non-avian dinosaurs (Hutchinson, 2004).

In the last three decades, CT scanning and related imaging techniques (like neutron scanning) have opened up exciting new avenues for non-destructive investigations of the structure of fossils. Initially these studies were conducted on medical CT units with relatively low resolution, but recently micro- and even nanolevel imaging has become possible (Sanchez et al., 2012). Histology has also become a major tool for studying the hard tissues of fossils (Reisz et al., 2013). In particular, this approach has facilitated studies of growth patterns and reconstructions of metabolic rates in extinct vertebrates (Padian et al., 2004).

Recent advances in our understanding of the relationship between development and evolution in extant animals have provided a new area of research. For example, understanding of developmental regulation based on genomics combined with geochemical data for palaeoenvironmental reconstruction has shed much light on the initial diversification of multicellular animals (Erwin et al., 2011). It is now possible to test, for the first time, hypotheses of development and growth in extinct organisms by using developmental data from extant forms. Cutting-edge research in this area includes investigations of past evolutionary events with molecular and developmental studies on living organisms (Rota-Stabelli et al., 2011; Gehrke et al., 2015).

The overarching challenge to paleontology in the coming decades is the integration of palaeobiology with evolutionary 
biology, but with a good understanding of what evolutionary questions can be addressed within the context of the fossil record. Balance is key, because reductionist explanations of major evolutionary events do not conform to current standards of modern evolutionary biology. It is in many ways counterproductive to propose simple hypotheses based on single causal relationships between biological or geological events and such complex major phenomena as the co-evolution of terrestrial plants and animals or major extinction events. Modern evolutionary biology has revealed the complex interactions between biological

\section{References}

Caron, J.-B., Gaines, R. R., Aria, C., Mangano, M. G., and Streng, M. (2014). A new phyllopod bed-like assemblage from the Burgess Shale of the Canadian Rockies. Nat. Commun. 5:3210. doi: 10.1038/ncomms4210

Clack, J. A. (2009). The fin to limb transition: new data, interpretations, and hypotheses from paleontology and developmental biology. Annu. Rev. Earth Planet. Sci. 37, 163-179. doi: 10.1146/annurev.earth.36.031207.124146

Dunne, J. A., Labandeira, C. C., and Williams, R. J. (2014). Highly resolved early Eocene food webs show development of modern trophic structure after the end-Cretaceous extinction. Proc. R. Soc. B 281:20133280. doi: 10.1098/rspb.2013.3280

Edgecombe, G. D. (2010). Arthropod phylogeny: an overview from the perspectives of morphology, molecular data and the fossil record. Arthropod Struct. Dev. 39, 74-87. doi: 10.1016/j.asd.2009.10.002

Erwin, D. H., Laflamme, M., Tweedt, S. M., Sperling, E. A., Pisani, D., and Peterson, K. J. (2011). The Cambrian conundrum: early divergence and later ecological success in the early history of animals. Science 334, 1091-1097. doi: $10.1126 /$ science. 1206375

Gehrke, A. R., Schneider, I., de la Calle-Mustienes, E., Tena, J. J., Gomez-Marin, C., Chandran, M., et al. (2015). Deep conservation of wrist and digit enhancers in fish. Proc. Natl. Acad. Sci. U.S.A. 112, 803-808. doi: 10.1073/pnas.1420208112

Gill, P. G., Purnell, M. A., Crumpton, N., Brown, K. R., Gostling, N. J., Stampanoni, M., et al. (2014). Dietary specializations and diversity in feeding ecology of the earliest stem mammals. Nature 512, 303-305. doi: 10.1038/nature13622

Hutchinson, J. R. (2004). Biomedical modeling and sensitivity analysis of bipedal running ability. II. Extinct taxa. J. Morphol. 262, 441-461. doi: 10.1002/jmor.10240

McInerney, F. A., and Wing, S. L. (2011). The Paleocene-Eocene Thermal Maximum: a perturbation of carbon cycle, climate, and biosphere with implications for the future. Annu. Rev. Earth Planet. Sci. 39, 489-516. doi: 10.1146/annurevearth-040610-133431 and earth systems that defy simple explanations. Bridging the understanding of macro- and microevolutionary processes has been a historical challenge for paleontologists and evolutionary biologists and should continue to be the primary goal for students in both research areas.

\section{Acknowledgments}

We thank Prof. H. Bucher and Dr. Peter D. Roopnarine for their helpful comments on a draft of this editorial.

Padian, K., Horner, J. R., and de Ricqlès, A. (2004). Growth in small dinosaurs and pterosaurs: the evolution of archosaurian growth strategies. J. Vert. Paleontol. 25, 555-571. doi: 10.1671/0272-4634(2004)024[0555:GISDAP] 2.0.CO;2

Raup, D. M. (1986). Biological extinction in earth history. Science 231, 1528-1533. doi: $10.1126 /$ science. 11542058

Reisz, R. R., Huang, T., Roberts, E. M., Peng, S., Sullivan, C., Stein, K., et al. (2013). Embryology of Early Jurassic dinosaur from China with evidence of preserved organic remains. Nature 496, 210-214. doi: 10.1038/nature11978

Rota-Stabelli, O., Campbell, L., Brinkmann, H., Edgecombe, G. D., Longhorn, S. T., Peterson, K. J., et al. (2011). A congruent solution to arthropod phylogeny: phylogenomics, microRNAs and morphology support monophyletic Mandibulata. Proc. Biol. Sci. 278, 298-306. doi: 10.1098/rspb. 2010.0590

Sanchez, S., Ahlberg, P. E., Trinajstic, K. M., and Mirone, A. (2012). Threedimensional synchrotron virtual paleohistology: a new insight into the world of fossil bone microstructures. Microsc. Microanal. 18, 1095-1105. doi: $10.1017 /$ S1431927612001079

Wills, M. A., Barrett, P. M., and Heathcote, J. F. (2008). The modified gap excess ratio $\left(\mathrm{GER}^{*}\right)$ and the stratigraphic congruence of dinosaur phylogenies. Syst. Biol. 57, 891-904. doi: 10.1080/10635150802570809

Conflict of Interest Statement: The authors declare that the research was conducted in the absence of any commercial or financial relationships that could be construed as a potential conflict of interest.

Copyright (C) 2015 Reisz and Sues. This is an open-access article distributed under the terms of the Creative Commons Attribution License (CC BY). The use, distribution or reproduction in other forums is permitted, provided the original author(s) or licensor are credited and that the original publication in this journal is cited, in accordance with accepted academic practice. No use, distribution or reproduction is permitted which does not comply with these terms. 